\title{
Avaliação dos agentes isolados e perfil de sensibilidade aos antibióticos nas uroculturas efetuadas na área de influência e região envolvente da USF da Barrinha - Esmoriz
}

Tiago Carvalho, ${ }^{1}$ José Lima Nogueira, ${ }^{2}$ Inês Trigo, ${ }^{2}$ Constança Oliveira, ${ }^{2}$ Luís Melo ${ }^{2}$

\section{RESUMO}

A resistência aos antibióticos é uma ameaça à saúde pública, em parte devido ao uso indiscriminado de antibióticos. As infeções do trato urinário (ITU) são as segundas mais frequentes na comunidade, sendo a Escherichia coli (E. coli) o microrganismo mais frequente. Para uma correta terapêutica empírica é fundamental realizar a monitorização do perfil de sensibilidade aos antibióticos. Esse constitui o objetivo deste trabalho.

Realizou-se um estudo do tipo observacional, descritivo e retrospetivo, no qual foram avaliados os resultados laboratoriais das uroculturas efetuadas entre 01/07/2015 e 30/06/2017 em vários postos de colheita do Laboratório Unilabs, na nossa área de influência. Com os dados fornecidos foi avaliada a sensibilidade aos antibióticos dos agentes isolados na população em estudo, tendo sido feita uma comparação por sexo $(p<0,05)$.

Obtiveram-se 6.584 uroculturas, das quais $14,4 \%$ positivas; destas, $74,3 \%$ eram referentes ao sexo feminino. A estirpe predominante foi a $E$. coli (61,03\%), seguida da Klebesiella pneumoniae (7,81\%) e Proteus mirabilis (6,23\%). De forma global, os agentes isolados foram sensíveis à cefixima em $92,5 \%$, à fosfomicina em $89,9 \%$, à nitrofurantoína em $82,9 \%$ e à amoxicilina/ácido clavulânico em 82,9\%. Relativamente ao sexo feminino verifica-se uma sensibilidade das estirpes à cefixima de $95,52 \%$, à fosfomicina de 91,49\%, à moxifloxacina de 90,60\% e à cefuroxima de 89,15\%. A sensibilidade à nitrofurantoína foi de $84,08 \%$. Em relação à amoxicilina/ácido clavulânico e à ciprofloxacina, a sensibilibadade das estirpes foi de $85,74 \%$ e $85,8 \%$, respetivamente.

Relativamente ao sexo masculino releva-se a taxa de sensibilidade à cefixima de $79,55 \%$, à levofloxacina de $79,37 \%$ e à fosfomicina de $80,69 \%$. Foram encontradas taxas de sensibilidade inferiores às do sexo feminino em todos os antibióticos avaliáveis, com exceção do cotrimoxazol, tetraciclina e ceftriaxone.

Os dados obtidos são concordantes com outros estudos e com as normas de orientação clínica da Direção-Geral da Saúde confirmando a adequação destas recomendações à nossa população. Este trabalho representa uma importante contribuição para o conhecimento do nosso contexto epidemiológico, permite uma abordagem terapêutica das ITU dirigida e fundamentada e é decisiva para a redução das resistências aos antibióticos.

Palavras-chave: Infeções do trato urinário; Escherichia coli; Resistência aos antibióticos; Comunidade; Terapêutica empírica; Sensibilidade antibiótica; Uroculturas.

1. Assistente MGF na USF Barrinha em Esmoriz.

2. Interno Formação Específica MGF da USF Barrinha, Esmoriz. 


\section{INTRODUÇÃO}

1 resistência aos antibióticos (RA) é um fenómeno natural, considerado uma importante ameaça à saúde pública, levando cada vez mais ao aumento dos custos, ao insucesso terapêutico e à morte. ${ }^{1}$ Trata-se de um problema grave, mundial, que afeta tanto países desenvolvidos como em desenvolvimento ${ }^{2}$ e deve-se a vários fatores, entre os quais o uso indiscriminado de antibióticos.

Em 2001, a Organização Mundial da Saúde (OMS) assumiu a RA como um problema prioritário, sendo instituídas medidas globais para o seu controlo, como a educação dos prescritores, a regulamentação da promoção de antibióticos pela indústria farmacêutica e a vigilância das resistências. ${ }^{2}$

As infeções do trato urinário (ITU), depois das infeções respiratórias, são as mais frequentes na comunidade, tendo maior incidência no sexo feminino. ${ }^{3}$

Os microorganismos etiológicos mais frequentemente associados às ITU são as bactérias aeróbias gram-negativas, sendo a Escherichia coli (E. coli) a responsável por cerca de 75 a 90\% dos casos de ITU. São também frequentes a Klebsiella pneumoniae, Proteus mirabilis, Pseudomonas aeruginosa e os gram-positivos Staphylococcus spp. ${ }^{4}$

Um estudo português de $2010^{5}$ identificou a E. coli em $73,3 \%$ das ITU, P. mirabilis em 7,6\%, K. pneumoniae em $7,5 \%$, E. faecalis em $3,5 \%$ e a $P$. aeruginosa em $3,1 \%$ na região do Vale do Sousa e Tâmega. Outro estudo de 2014, ${ }^{6}$ realizado na Região Centro de Portugal, identificou a $E$. coli em 65,9\% dos casos, K. pneumoniae em 12\%, P. mirabilisem $7 \%$, E. faecalis em 4,8\% e P.aeruginosa em 2,7\%.

A resistência dos microrganismos aos antibióticos varia com o consumo dos mesmos, verificando-se uma menor prevalência de resistência antibiótica nos países do norte da Europa, onde o consumo é menor. ${ }^{7}$

Estima-se que entre 50 a $70 \%$ das mulheres têm uma ITU durante a vida e que 20 a 30\% têm episódios recorrentes. A antibioterapia empírica, para tratamento da cistite aguda, associa-se a taxas de erradicação microbiológica superiores a $90 \%{ }^{8}$ quando a decisão de prescrição se fundamenta no conhecimento dos principais agentes envolvidos e se conhece o seu perfil de sensibilidade.

Assim, é fundamental a monitorização do perfil de sensibilidade dos antibióticos, de forma a orientar a terapêutica empírica. ${ }^{9}$
O presente estudo tem como objetivo determinar o perfil de sensibilidade aos antimicrobianos dos principais agentes infeciosos das ITU adquiridas na comunidade na região envolvente da USF da Barrinha - Esmoriz.

\section{MATERIAL E MÉTODOS}

Trata-se de um estudo do tipo observacional, descritivo e retrospetivo, no qual foram avaliados os resultados laboratoriais das uroculturas efetuadas entre 01/07/2015 e 30/06/2017 nos postos de colheita de Maceda, Ovar, Cortegaça, Esmoriz, Anta, Espinho, Lourosa e S. Félix da Marinha e cujos dados foram cedidos mediante solicitação pelo Laboratório Unilabs.

Com os dados fornecidos foi estudada a prevalência das uroculturas positivas, global e por sexo, as estirpes mais prevalentes e os resultados dos antibiogramas.

A análise estatística foi efetuada com recurso ao SPSS ${ }^{\circ}$ 25.0. A estatística descritiva utilizada para caracterizar a população em estudo incluiu frequências absolutas e relativas. O teste Qui-Quadrado de Pearson foi usado para comparar variáveis qualitativas. O nível de significância estatística utilizado foi $p \leq 0,05$ (2 caudas).

Foi também utilizado o Microsoft Excel® v. 2016.

\section{RESULTADOS}

A amostra foi constituída por 6.584 uroculturas, das quais $14,4 \%$ foram positivas, ou seja, com pelo menos uma estirpe bacteriana identificada.

O sexo feminino constituiu $74,3 \%$ da amostra, com 822 uroculturas positivas (Quadro I).

A estirpe predominante foi a $E$. coli $(61,03 \%)$, seguida de $K$. pneumoniae $(7,81 \%)$, P. mirabilis $(6,23 \%), S$. agalactiae (5,6\%), E. faecalis (4,01\%) e S. saprofhyticus $(2,75 \%)$ (Quadro II). A P. aeruginosa foi o agente isolado em cerca de $1 \%$ das uroculturas.

De forma global, os agentes isolados foram sensíveis à cefixima em 92,5\%, à fosfomicina em 89,9\%, à nitrofurantoína em 82,9\% e à amoxicilina/ácido clavulânico em $82,9 \%$ - Por outro lado, os antibióticos com menor taxa de sensibilidade foram a eritromicina $(45,40 \%)$ amoxicilina $(50,59 \%)$ e a clindamicina $(50,87 \%)$ (Quadro III).

Observando isoladamente o perfil das uroculturas relativas ao sexo feminino verifica-se uma sensibilida- 
QUADRO I. Distribuição da amostra por sexo e resultado das uroculturas

\begin{tabular}{l|c|c|c} 
Uroculturas & Total & Negativas & Positivas \\
\hline Feminino & $4.892(74,3 \%)$ & $4.070(83,2 \%)$ & $822(16,8 \%)$ \\
\hline Masculino & $1.692(25,7 \%)$ & $1.567(92,6 \%)$ & $125(7,4 \%)$ \\
\hline Total & 6.584 & $5.637(85,6 \%)$ & $947(14,4 \%)$
\end{tabular}

dos os antibióticos avaliáveis (Quadro III), sendo essa diferença estatisticamente significativa para os antibióticos comparados, com exceção do cotrimoxazol, tetraciclina e ceftriaxone (Quadro III). Relativamente ao ceftriaxone, embora não tenha atingido significância estatística $(p=0,061)$, houve uma tendência para uma maior sensibilidade no sexo feminino.

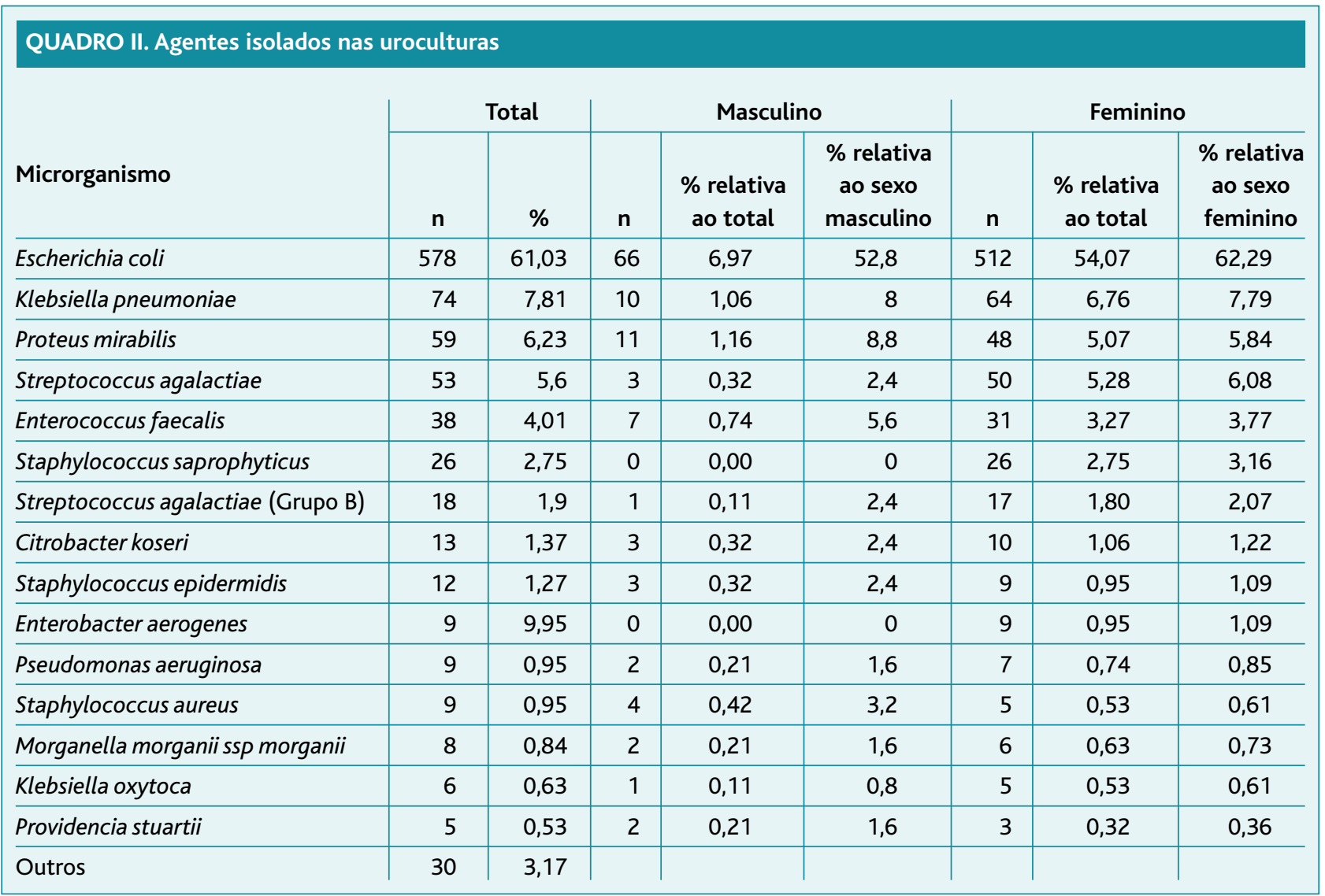

de das estirpes à cefixima de $95,42 \%$, à fosfomicina de 91,49\%, à moxifloxacina de 90,60\% e à cefuroxima de $89,15 \%$. A sensibilidade à nitrofurantoína foi de $84,08 \%$. Em relação à amoxicilina/ácido clavulânico e à ciprofloxacina, a sensibilibadade das estirpes foi de $85,74 \%$ e $85,8 \%$, respetivamente.

Analisando o perfil das uroculturas relativas ao sexo masculino releva-se a taxa de sensibilidade à cefixima de $79,55 \%$, à levofloxacina de $79,37 \%$ e à fosfomicina de $80,69 \%$. Foram encontradas taxas de sensibilidade inferiores às do sexo feminino em to-

\section{DISCUSSÃO}

As prevalências das estirpes encontradas no nosso estudo foram sobreponíveis às descritas na literatura, sobretudo em relação às três mais frequentes: $E$. coli, $K$. pneumoniae e Proteus. No entanto, a prevalência de $E$. coli $(61,03 \%)$ foi inferior à estimada nos referidos estudos, em que varia entre 66 e 73,3\%.3.5-6

A K. pneumoniae foi encontrada em $7,8 \%$ do total de uroculturas, resultado de acordo com a prevalência encontrada nos estudos já referidos e que varia entre 6 e $12 \%$. 
A antibioterapia empírica adequada para o tratamento da ITU deve basear-se no conhecimento dos principais agentes microbianos envolvidos e no seu perfil de sensibilidade aos antibióticos.

Encontrou-se uma elevada sensibilidade global $(89,9 \%)$ e no sexo feminino $(91,5 \%)$ à fosfomicina, o que, de acordo com a Direção-Geral da Saúde (DGS), ${ }^{8}$ permite a terapêutica empírica eficaz com este antibiótico.

Relativamente ao sexo masculino, apesar de sensibilidades mais baixas, a fosfomicina aparece com $81 \%$ de eficácia, seguida da cefixima e da levofloxacina com $80 \%$ e $79 \%$, respetivamente. A amoxicilina/ácido clavulânico apresenta uma cobertura de apenas $66 \%$, não sendo, desta forma, uma opção a considerar empiricamente neste subgrupo.

Em relação à nitrofurantoína e à amoxicilina/ácido clavulânico, a taxa de sensibilidade encontrada nesta população foi de $83 \%$, embora significativamente inferior nos doentes do sexo masculino.

A cefuroxima (cefalosporina de $2^{\text {a }}$ geração) apresentou uma cobertura de $86 \%$, em comparação com a cefixima ( $3^{\text {a }}$ geração) que apresentou $92,52 \%$ para a amostra global. Já o ceftriaxone apresentou uma cobertura baixa, na ordem dos $70 \%$. A cefixima e a cefuroxima podem ser uma opção nas pielonefrites. Já o ceftriaxone, apesar de recomendado nas pielonefrites graves pela norma da DGS, ${ }^{8}$ apresenta uma cobertura muito reduzida.

Em relação às quinolonas, a ciprofloxacina apresentou uma eficácia global de $84 \%$ enquanto a levofloxacina rondou os $90 \%$. As quinolonas não são consideradas terapêuticas de $1^{\text {a }}$ linha. Reserva-se a levofloxacina para casos de pielonefrite aguda ligeira a moderada em doentes intolerantes aos beta-lactâmicos. A ciprofloxacina não está indicada.

A norma de orientação clínica n. ${ }^{\circ}$ 15/2011 recomenda, no tratamento da cistite aguda não complicada, a nitrofurantoína, fosfomicina ou amoxicilina/ácido clavulânico. Os resultados do presente estudo vão ao encontro destas orientações, considerando a sensibilidade global dos agentes encontrados. Em contexto de ambulatório, estes resultados podem ser úteis para a prescrição empírica.

O presente estudo exibe limitações metodológicas inerentes ao seu desenho retrospetivo, não revendo as sensibilidades por agente, não fazendo uma análise por faixa etária e não tendo em conta o contexto clínico dos doentes, o que não permitiu outro tipo de conclusões. Também o facto de todos os dados serem de um labo- 
ratório e, portanto, com o recurso sempre à mesma técnica, é uma limitação ao estudo.

\section{CONCLUSÃO}

A terapêutica empírica das ITU é uma recomendação consensual que requer, no entanto, o conhecimento da prevalência das estirpes microbianas, bem como do seu perfil de sensibilidade.

As estirpes mais frequentes nas ITU da comunidade envolvente da USF da Barrinha - Esmoriz são a E. coli (61,03\%), seguida da Klebsiella pneumoniae $(7,81 \%)$ e do Proteus mirabilis (6,23\%). Apesar de as estirpes possuírem elevada sensibilidade quer à amoxicilina/ácido clavulânico $(82,92 \%)$ quer à fosfomicina $(89,91 \%)$, a primeira não tem vantagens comparativamente à segunda.

É de salientar que os trabalhos de caracterização de prevalência de microorganismos e seu perfil de resistências local ou regional se tornam imprescindíveis para melhor atuar numa abordagem individualizada das ITU no seu contexto geográfico e para contribuir para o esforço ainda necessário no percurso da redução das resistências aos antibióticos.

\section{AGRADECIMENTOS}

Os autores agradecem ao Dr. João Pedro Ramos (CMO - Director Médico Portugal Unilabs) e ao Laboratório Unilabs pela disponibilização dos resultados das uroculturas.

\section{REFERÊNCIAS BIBLIOGRÁFICAS}

1. European Centre for Disease Prevention and Control. Antimicrobial resistance surveillance in Europe. Stockholm: ECDC; 2015.

2. World Health Organization. WHO global strategy for containment of antimicrobial resistance [Internet]. Geneva:WHO; 2001. Available from: https://www.who.int/drugresistance/WHO_Global_Strategy_English .pdf

3. Costa MC, Pereira P, Bolotinha C, Ferreira A, Cardoso R, Monteiro C, et al. Frequência e susceptibilidade bacteriana em infecções urinárias: dados de um laboratório de Lisboa (parte II) [Frequency and bacterial susceptibility in urinary infections : data from a laboratory in Lisbon, Portugal (part II)]. Rev Lusófona Ciên Tecnol Saúde. 2009;6(1):87-103. Portuguese

4. Trautner BW, Gupta K. Urinary tract infections, pyelonephritis, and prostatitis. In: Longo DL, Fauci AS, Kasper DL, Hauser SL, Jameson JL, Loscalzo J, editors. Harrison's principles of internal medicine. 18th ed. New York: McGraw-Hill Professional; 2012. P. 2387-96. ISBN 9780071748896

5. Martins F, Vitorino J,Abreu A. Avaliação do perfil de susceptibilidade aos antimicrobianos de microrganismos isolados em urinas na região do Vale do Sousa e Tâmega [Evaluation of the antimicrobial susceptibility profile of microorganisms isolated from urine in the region of Vale do Sousa and Tâmega]. Acta Med Port. 2010;23(4):641-6. Portuguese

6. Passadouro R, Fonseca R, Figueiredo F, Lopes A, Fernandes C. Evaluation of the antimicrobial susceptibility of community-acquired urinary tract infection. Acta Med Port. 2014;27(6):737-42.

7. Goossens H, Ferech M, Vander Stichele R, Elseviers M. Outpatient antibiotic use in Europe and association with resistance: a cross-national database study. Lancet. 2005;365(9459):579-87.

8. Direção-Geral da Saúde. Terapêutica de infeções do aparelho urinário (comunidade): norma da DGS n. ${ }^{\circ}$ 15/2011, de 30/08/2011. Lisboa: DGS; 2011.

9. Baerheim A. Empirical treatment of uncomplicated cystitis. BMJ. 2001;323(7323):1197-8.

\section{CONFLITO DE INTERESSES}

Os autores declaram não ter quaisquer conflitos de interesse.

\section{FONTES DE FINANCIAMENTO}

Este trabalho não recebeu qualquer contribuição, subsídio ou bolsa.

\section{ENDEREÇO PARA CORRESPONDÊNCIA}

Tiago Carvalho

E-mail: tiagofilipecarvalho@gmail.com

https://orcid.org/0000-0003-3380-071X

Recebido em 22-09-2017

Aceite para publicação em 20-09-2019 


\section{ABSTRACT}

\section{EVALUATION OF ISOLATED AGENTS AND ANTIBIOTIC SENSITIVITY PROFILE IN URINE CULTURES CARRIED OUT IN THE AREA OF INFLUENCE AND SURROUNDING REGION OF THE USF BARRINHA - ESMORIZ}

Antibiotic resistance is a major public health threat, mainly due to its indiscriminate use. Urinary tract infections are the second most frequent in the community. Thus, we consider it is essential to monitor the antibiotic sensitivity profile in order to prescribe proper empirical therapy. This was the main objective of this work.

We carried out an observational, descriptive, retrospective study. The laboratory results from urine cultures collected at several Unilabs Laboratory collecting points situated in our area of influence, between $1^{\text {st }}$ July 2015 and $30^{\text {th }}$ June 2017, were assessed. With the provided data, antibiotic susceptibility of the isolated agents was evaluated in this population and a comparison between genders was performed $(p<0.05)$.

We obtained 6,584 urine cultures, $14.4 \%$ of which were positive. The female sex contributes to $74.3 \%$ of the positive results. The predominant strain was E. coli (61.03\%), followed by K. pneumoniae (7.81\%) and P. mirabilis (6.23\%). Overall, the isolated agents were sensitive to cefixime in $92.5 \%$, fosfomycin in $89.9 \%$, nitrofurantoin in $82.9 \%$, and amoxicillin/clavulanic acid in $82.9 \%$. Regarding the female sex, we detected a sensitivity of the strains to cefixime of $95.52 \%$, fosfomycin of $91.49 \%$, moxifloxacin of $90.60 \%$ and cefuroxime of $89.15 \%$. The sensitivity to nitrofurantoin was $84.08 \%$. In relation to amoxicillin/clavulanic acid and ciprofloxacin, the susceptibility of the strains was $85.74 \%$ and $85.8 \%$ respectively. Regarding the male gender, the cefixime sensitivity rate was $79.55 \%$, levofloxacin was $79.37 \%$, and fosfomycin $80.69 \%$. We found lower sensitivity rates for females in all evaluable antibiotics, with the exception of cotrimoxazole, tetracycline, and ceftriaxone.

The obtained data is in agreement with other studies and with the official recommendations from the Portuguese DGS attesting their suitability to our population. This type of work is essential to an individualized approach to UTIs based in our epidemiology data and constitutes a strong contribution to antibiotic resistance reduction effort.

Keywords: Urinary tract infections; Escherichia coli; Antibiotic resistance; Community; Empirical therapy; Antibiotic sensitivity; Urine cultures. 